\title{
Unpacking the Concept of Bioeconomy: Problems of Definition, Measurement, and the Attribution of 'Value'
}

\author{
James Mittra \\ Science, Technology and Innovation Studies, School of Social and Political Science, University of Edinburgh, \\ UK/james.mittra@ed.ac.uk \\ Giorgos Zoukas \\ Science Technology and Innovation Studies, School of Social and Political Science, University of Edinburgh, \\ UK
}

\begin{abstract}
In this paper, we critically explore the evolution and impact of the concept 'bioeconomy' as a descriptor and driver of different scientific, technological, and policy initiatives in the life sciences. We unpack the different ways bioeconomy has been framed - as an emergent, present, or sometimes promissory economic regime underpinned by particular socio-technical practices - by tracing how its use has evolved in different disciplinary field and sectors. We also critically analyse three key reports that attempt to measure the size and contribution of the bioeconomy at regional levels. Our overarching questions are: What is the bioeconomy, how has it been used in different fields, and how might it be best understood and valued both economically and politically? In answering these questions, we build on and contribute to critical scholarship in science and technology studies, particularly theoretical work on biovalue, commodification, and assetisation; using this in conjunction with our empirical concept search and document analysis to contribute new knowledge and understanding of the bioeconomy's past, present, and future.
\end{abstract}

Keywords: bioeconomy, measurement, value, practices, promissory expectations, neoliberal

\section{Introduction}

In this paper we explore the evolution and impact of the concept 'bioeconomy', as a descriptor of various scientific, technological, and policy initiatives in the life sciences. We unpack the different framings of bioeconomy, or more accurately 'bioeconomies' (Pavone and Goven, 2017), which are driving different and often incompatible concep- tions of value and benefit. Our overarching questions are: what is the bioeconomy, how has it been used in different fields, and how might it be best understood and valued? This is not straightforward given the ephemeral and speculative nature of the bioeconomy; the diverse disciplines within which the concept has acquired salience, and the 
lack of consistency in the definition and categorization of its objects. The latter issue becomes critical when policymakers try to measure the size and overall contribution of the bioeconomy at national or regional levels. There has so far been no comprehensive and systematic attempt to trace the emergence of bioeconomy as a concept in different disciplinary fields, and link this to emerging theories of value and valuation practices. This paper therefore makes an important contribution to the social study of bioeconomy by using empirical evidence from a broad literature analysis to critically reflect on bioeconomy's different framings, and address the policy implications for measurement and the attribution of value.

Bioeconomy appears to be an emergent, present, but also promissory economic regime built on the exploitation of old and new biological resources. What we mean by promissory is that much of its value is speculative; based on estimations of future potential rather than current reality. Some even describe it as a 'neoliberal' political project (Goven and Pavone, 2015). The concept is frequently cited within academic and policy literatures, yet it remains ambiguous and contested. The definition of bioeconomy, which depends on how its material objects and practices are included or excluded within classificatory regimes (Bowker and Star, 2000), also has sociopolitical and economic consequences. Classification systems and the standards they embody are usually adopted to create order and stability in an uncertain world. However, we will show in the case of bioeconomy that decisions about how to order and classify different sectors and activities may obfuscate as much as they reveal. A certain ambiguity may be intentional, as policymakers must justify public investments in biotechnology and make good on powerful narratives of future promise. The bioeconomy might be considered 'performative' in the parlance of economic sociology (Callon et al., 2002). For example, governments and industry embrace life science innovation as a driver of economic and social prosperity, and this shapes the organisational structure and R\&D options available to actors in the sector (Mittra, 2016).

There are nevertheless different framings of the bioeconomy, and competing narratives about the contributions of the underlying science, technology, and material products. There is also recognition that multiple value(s) and valuation practices, beyond simply the economic, underpin the bioeconomy (Helgesson and Kjellberg, 2013; Lamont, 2012; Mittra, 2016). We suggest these multiple framings generate, within science/innovation communities and amongst critical social scientists, both promissory (Borup et al., 2006) and more cautious narratives around value and benefit.

In this paper, we unpack the concept of bioeconomy and reveal the different narratives of value, benefit, and worth that underpin it. We begin by presenting findings of a broad literature analysis we concluded in July 2018. Our aim was to trace the origins and use of the concept bioeconomy in the academic literature over time (from its first use until the end of 2017) in the sectors of health/ medicine (red biotechnology), agriculture/food (green biotechnology), and energy/environment (white biotechnology). This gave us a sense of the concept's provenance and evolution, and revealed salient differences in its definition and use.

We then explore in depth different framings of bioeconomy. We discuss the bioeconomy as simultaneously a neoliberal political project to improve national competitiveness, and a scientific/technological project to meet global challenges such as climate change, food security, and health. The desire to generate new types of value from the monetisation of both old and new biological processes and technologies, in the context of these global challenges, illustrates the socio-political and economic issues at stake. Next, we critique three key reports (examples from the UK, US, and Europe) that attempt to measure the size and overall contribution of the bioeconomy using conventional metrics of value. We focus on these advanced economies because they have been at the forefront of innovation in life sciences and have most fully embraced the concept of bioeconomy in policy and practice. Given ambiguities around the bioeconomy concept, and its impact on different industrial and policy sectors, in the final section we consider the normative question of whether embracing a broader definition of value (beyond the economic) would help us better assess the bioeconomy's future. 
In reflecting on our empirical data, we draw critically on a range of theories that have emerged around biovalue, commodification, and assetisation that we consider opens up possibilities for a more nuanced and broader approach to thinking about value and valuation processes. By opening up the concept of value to include the social practices of valuation, we suggest the bioeconomy can be explored in a more sophisticated and interesting way. So on the one hand, we identify the tensions between framing and theorising the bioeconomy as a political, neoliberal project, or alternatively a strictly scientific/ technological project. On the other hand, we try to understand how different theories of value and valuation ('commodity' versus 'asset' for instance), might help us gain purchase on the techniques of measurement that are being used in policy contexts to promote a particular ideal of bioeconomy. Given so much of the value ascribed to the bioeconomy is speculative, we also draw on the sociology of expectations and socio-technical imaginaries, where appropriate, to illuminate and reflect on our data.

\section{Methods}

We conducted a systematic literature search and concept analysis, which was completed in July 2018, with the primary aim of identifying published material that explicitly used the term 'bioeconomy' and its close variants. In addition to the main search term 'bioeconomy/bio-economy', we also searched 'biobased/bio-based economy' up until the end of 2017 to ensure we had data for a complete set of years. Many authors treat biobased economy and bioeconomy as synonymous, although Hausknost et al (2017) suggest technically bioeconomy refers to methods of converting raw material into bio-products, whilst bio-based economy refers to the raw material itself. We do not draw such a strict distinction in this paper. The published material covered peer-reviewed journal articles, some books and book chapters; and 'grey' literature, such as conference proceedings and abstracts, meeting reports, working papers, presentations, technical notes, annual reports, bulletin articles, and governmental and non-governmental reports.
Our search was conducted using 16 databases: AMED; ASSIA (Applied Social Science Index and Abstracts); BioMed Central; BIOSIS Citation Index; Business Source Complete; CAB Abstracts; CINAHL Plus- Cumulative Index to Nursing and Allied Health Literature; Cochrane Library; Congressional Record; Department of Health; Econlit; EMBASE; MEDLINE; IBSS (Social Science Premium Collection); Web of Science; and PubMed. The total number of hits across all databases, before we undertook a selection process and removed duplicates, was 5,313. Web of Science and IBSS generated the most hits with 1,780 and 1,352 respectively. The initial search was applied to the full texts of the unsorted articles in each database, with the main inclusion criteria being that the documents include a discussion, or at least mention, of the primary search terms. The titles, publication dates, URLs, and, where applicable or possible, the specific research fields and abstracts of the selected documents were then copied into an Excel spreadsheet file.

A total of 1,064 papers in the English language, published between 1992 (the first time an article that met our search criteria appeared) until the end of 2017, were then selected on the basis of perceived relevance. All included the search term in either the title or abstract, indicating the importance attached to the concept. The academic papers, which constitute the majority of our selected material, covered research areas from the natural, social, and applied sciences; and academic disciplines and interdisciplinary fields such as biology, chemistry, economics, law, innovation studies, geography, sociology, science and technology studies; education, medical sciences, materials science, environmental sciences, and agricultural sciences. Non peer-reviewed and more generalist documents, including policyoriented documents and reports were also identified and categorized separately from the academic papers. Our final categorization sought to differentiate peer-reviewed academic papers from the natural sciences and the social sciences (our primary focus) and this broader gray literature, where we prioritized official governmental and non-governmental reports.

The purpose of the search was to reveal and sensitise us to how the concept of bioeconomy 
had been used over time, in different academic fields, to complement our subsequent investigation of how the concept has been framed by different constituencies and stakeholders. Following the creation of the spreadsheet, Mittra (Lead Author) read through the abstracts of all articles, and scanned the full texts in some cases, to categorize the papers into the broad fields of white (industrial biotechnology/sustainable energy), red (health/pharmaceuticals), green (agriculture and food), and blue biotechnology. Blue refers to cases where it was not clear that the paper contributed entirely or mainly to one field. Blue biotechnology conventionally refers to marine biotechnology/aquaculture, but given we found so few articles in this specific field, we classified them alongside green biotechnology, reserving the blue category for those articles lacking specificity. In subsequently categorizing the papers according to whether they were from the social sciences, natural sciences, or 'other', we were able to identify salient patterns over time. This exercise was sufficient for our purpose of providing an overview of how the concept evolved in the literature over the given time period. We could have categorized the papers further into multiple sub-disciplines, but it is not clear how useful or accurate this would have been. Others have provided more detailed and comprehensive systematic reviews using citation data at the disciplinary level (Bugge et al., 2016; Golembiewski et al., 2015), and we refer to this work and its data to complement our own analysis.

Certain caveats are necessary to clarify the limitations of our method and the knowledge claims we can make. First, we note that there is an inherent subjective element to the choice of search criteria and the categorization of the papers. In many cases, the distinction between social science and natural science is blurred, e.g. environmental science, which embraces both natural and social scientific approaches. The same is true for the distinction between white and green biotechnology. For instance, where biotechnology is used to improve crop development for biofuels, this could reasonably be classed as both green and white biotechnology. There will always be some overlap at the boundaries of disciplines and fields, so some of our category decisions were inevitably subjective. Alternative classificatory decisions could have been justified. In those cases where a paper contributed to more than one field, a decision was made to choose what we judged to be the predominant field. If the paper was contributing equally to more than one field, or where a decision on predominant field could not be ascertained, we categorized the paper as 'blue'. The latter were mainly policy-oriented documents or reports, as well as broader review pieces.

Second, the range of databases chosen, and the search terms used, may not have captured all articles addressing salient themes relevant to the bioeconomy. Many more articles would have been captured if we had included 'biotechnology', 'life sciences', or 'genomics' in our search (all of which discuss similar themes). However, given our primary interest was in the evolution and use of a new term called 'bioeconomy' or 'bio-based economy', as a signifier of novel activities and practices, limiting the search criteria was justified. Our results are broadly consistent with the findings of those who have conducted bibliometric/citation research on bioeconomy. In the following section, we summarise the key findings from our literature analysis, before unpacking and critically exploring the concept and its framing in more detail.

\section{Tracking use of the term bioeconomy over time: Key findings from literature analysis}

Our findings reveal that the use of the term bioeconomy, or biobased economy, has increased over time, particularly from 2006 onwards, as illustrated in Figure 1. Before 2004, only 15 articles met our final inclusion criteria. Since then there has been a steady increase in the total number of articles that explicitly reference the term in the title or abstract, with a particularly high number in the period 2014-2017. We surmise that the Organisation for Economic Cooperation and Development's (OECD) 2006 report The Bioeconomy to 2030: Designing a Policy Agenda (OECD, 2006), which we disucss later, became a key document that helped drive the salience of the concept and played an important role in popularising the term in a variety of academic disciplines. 
Figures 2 and 3 show the number of publications by broad disciplinary area (social science, science, and policy/non peer-reviewed grey literature) and by field/sector respectively. Figure 4 displays the publications by field in each disciplinary category to show differences in how social science and natural sciences, in particular, have prioritised certain approaches to bioeconomy.

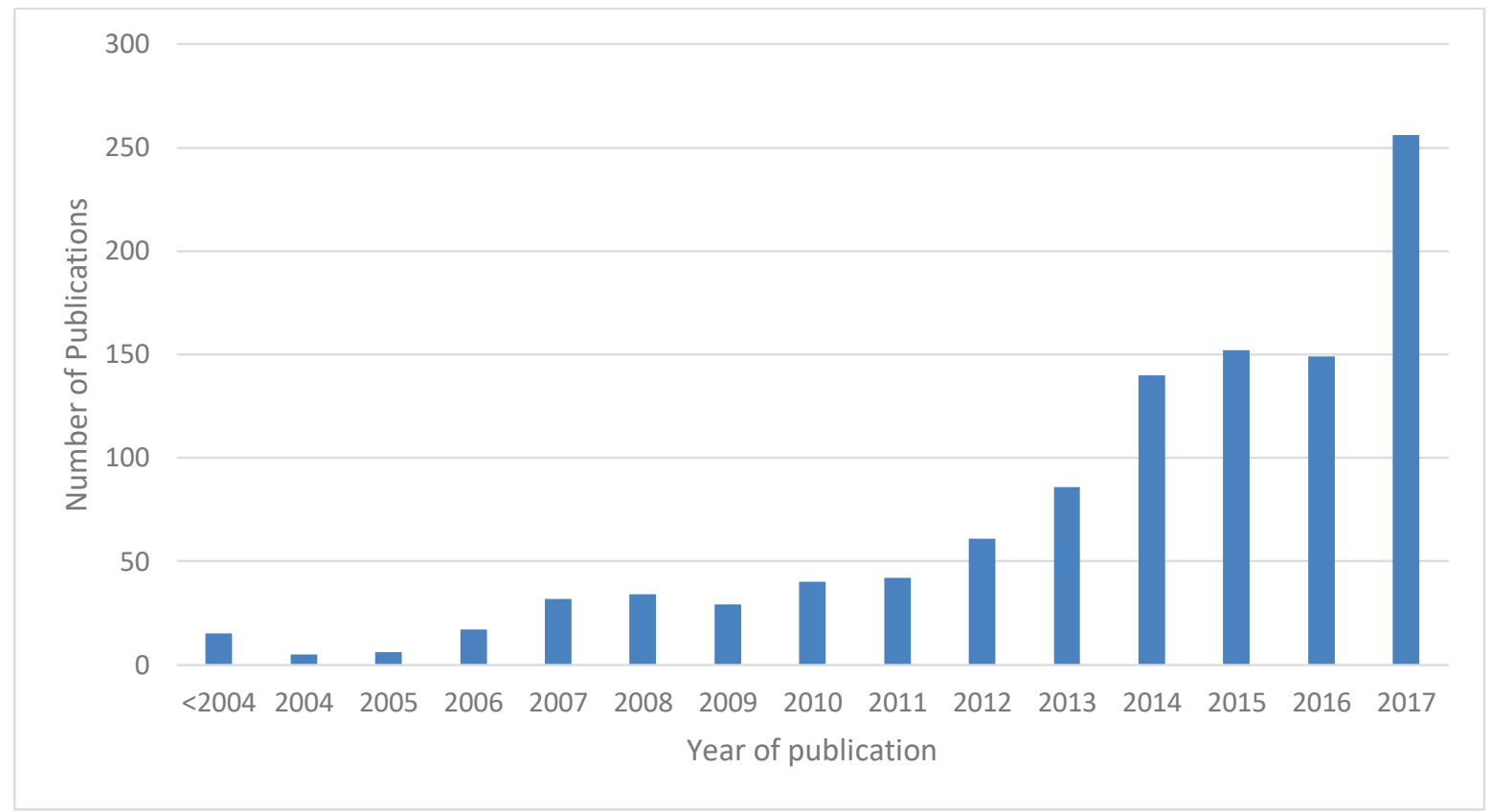

Figure 1. Total Number of Publications by Year Using the Term Bioeconomy or its Variants.

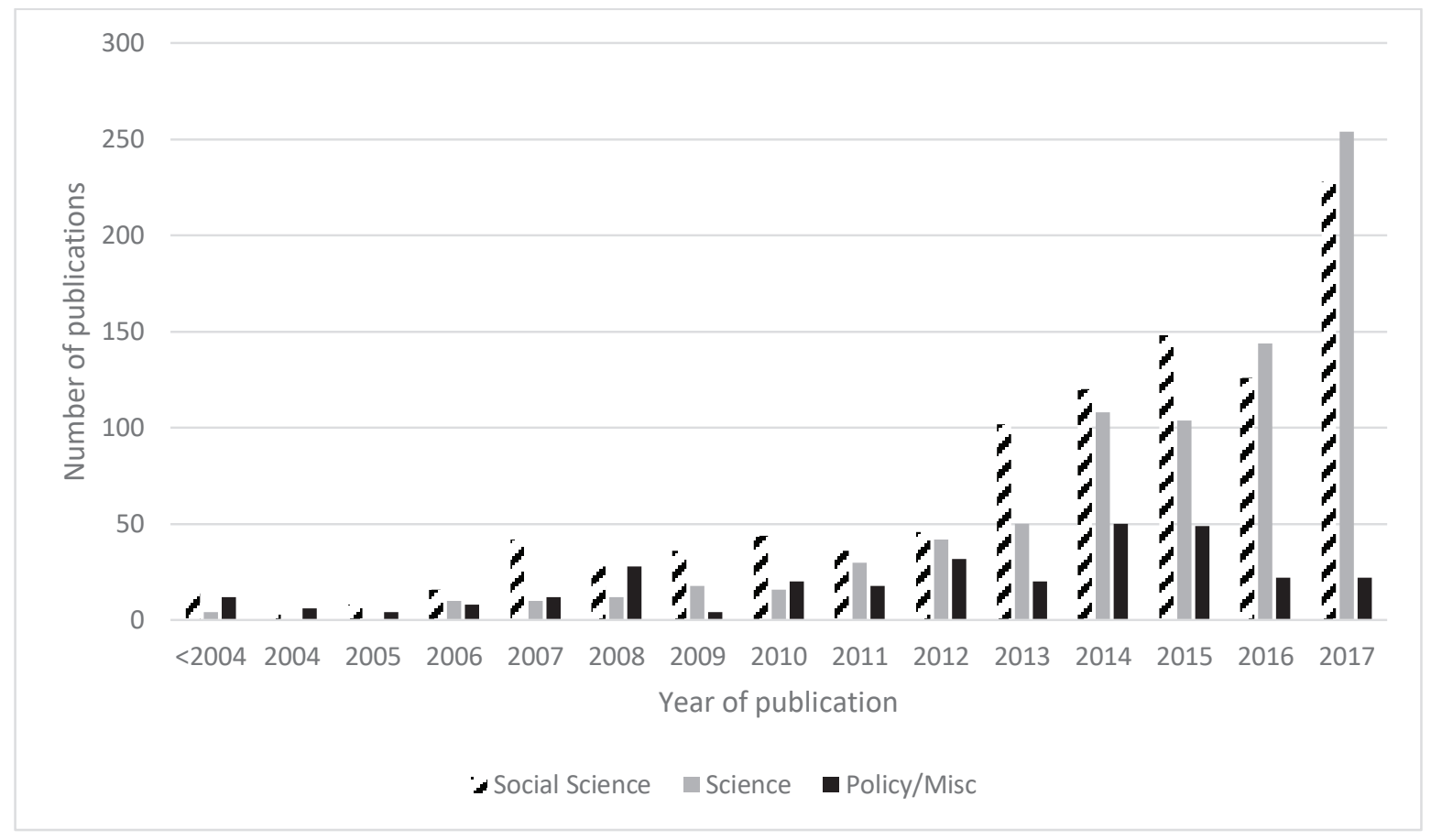

Figure 2. Publications by Broad Disciplinary Area. 


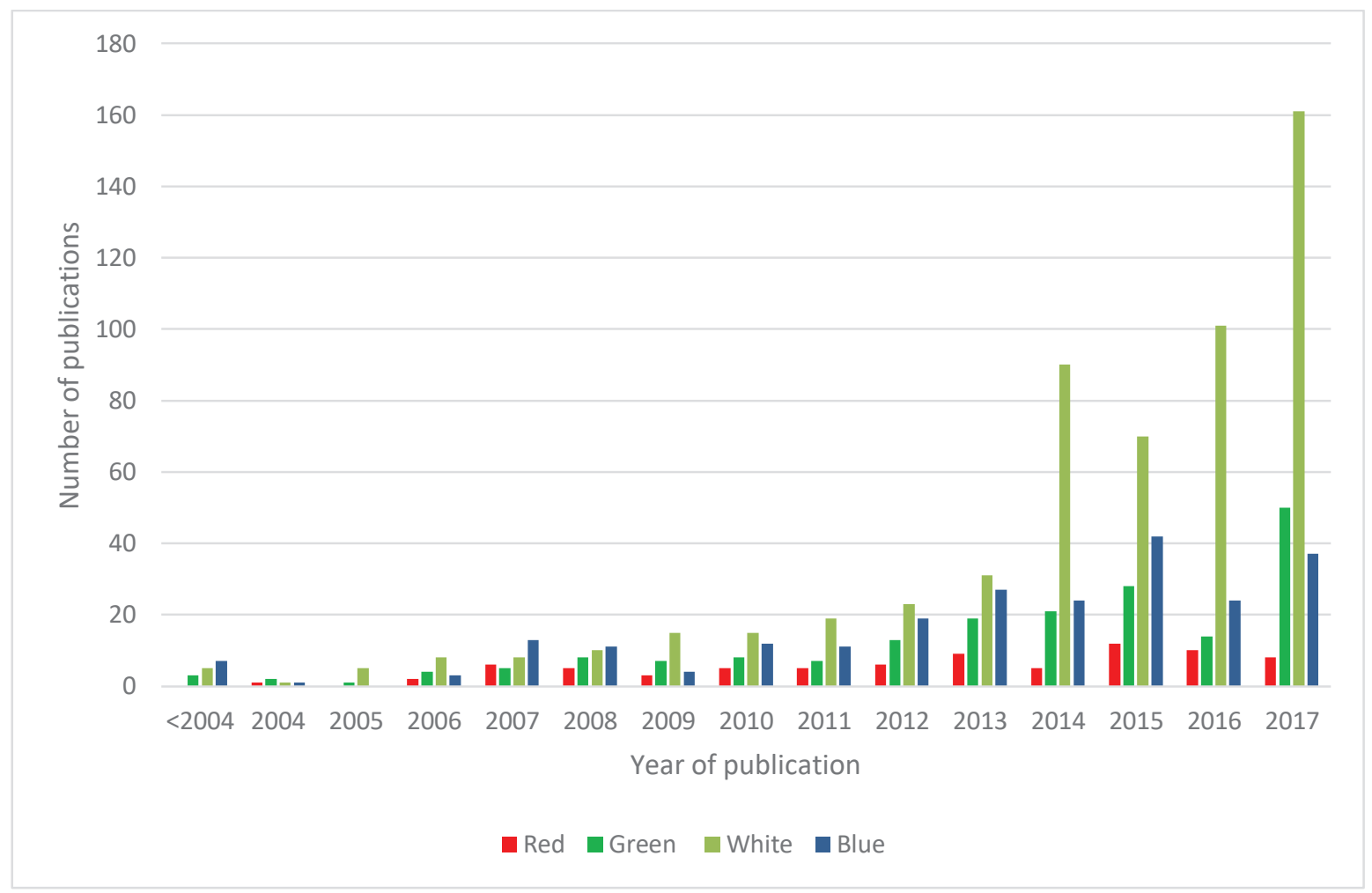

Figure 3. Publications by Field/Sector.

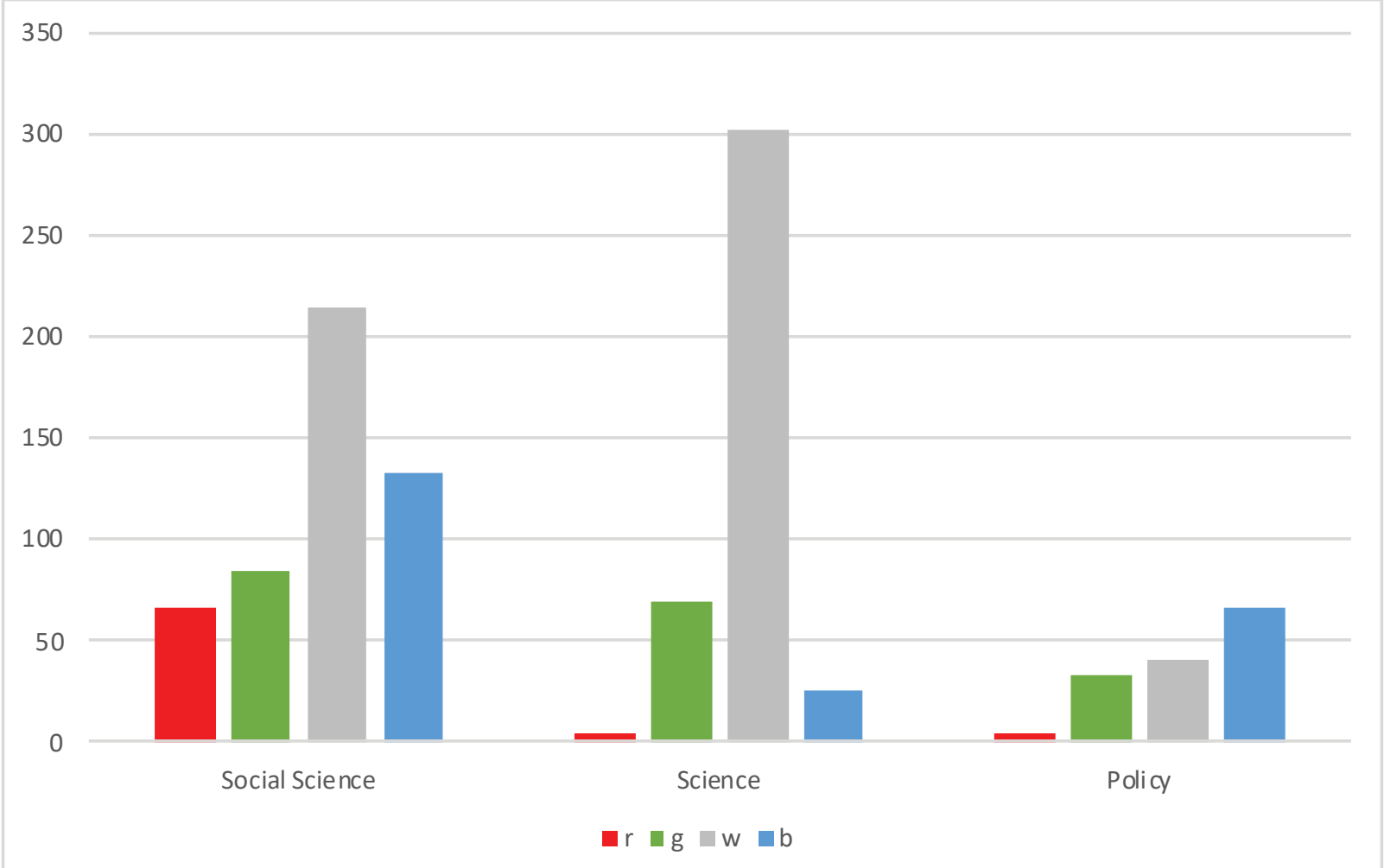

Figure 4. Publications by Field in Each Category. 
In terms of broad disciplinary area (Figure 2) we can see that, apart from 2016 and 2017, slightly more peer-reviewed articles in our final selection came from the social sciences, rather than the natural sciences. However, we note our earlier caveat that the boundaries can be blurred in some cases. Nevertheless, the patterns of growth in the social science articles do not neatly follow those of the policy and science-based articles, which suggests that the disciplines have their own momentum. We did not attempt to classify the sub-disciplines within each general field, but Bugge at al. (2016) have in their comprehensive citation analysis. They found that amongst the broad diversity of disciplines in the sciences that have engaged with the term bioeconomy, the natural and engineering sciences have taken a predominant role, with the Web of Science categories 'Biotechnology and Applied Microbiology' and 'Energy and Fuels' constituting a 25\% share of the total papers that the authors identified. This confirms our own search results from Web of Science.

However, the publications by general field/ sector data (Figure 3) is more revealing. From 2006, we can see that in each year most of the publications were within the category white biotechnology, followed by blue (non-specific), then green biotechnology, and finally red biotechnology. So where it was possible to clearly identify a lead sector, white biotechnology was by some margin the one most likely to generate articles explicitly referencing bioeconomy. If we then look at publications by sector in each disciplinary category (Figure 4), we see that for natural sciences, white biotechnology is a clear leader with 301 papers, followed by green biotechnology (69), then blue (26), and finally red (5). For social sciences, white was still predominant (214 papers), but blue (133), green (85), and red (67) biotechnology were also far more likely to be represented than for the scientific disciplines. For our Policy/ Misc field, white and blue biotechnology tended to be most common, with green biotechnology not far behind, but red biotechnology was very low with only 5 documents. We do note that the Policy/Misc category is not as comprehensive as the social and natural sciences categories. This is because we had to be far stricter on inclusion criteria (official and significant reports) as this category could have included press releases, news items, conference posters etc that would have created an unmanageable and not particularly useful dataset. As such, the total number of documents in this category was small in comparison to the other categories, which are our main focus.

Of those papers that were in the field of red biotechnology, or the non-specific blue category (Figure 4), it is a significant finding that these were predominantly social science papers, which suggests that social scientists' understanding of and intellectual interest in, the bioeconomy does not align with that of the natural scientists. To be sure, there is still high engagement with white biotechnology, as there is in the natural sciences. We should clarify here that most of the social science papers discussing white biotechnology were generally environment focused (risk assessment, economic analyses, survey research etc) in the context of biofuel development or sustainable agriculture/forestry. This was an area where the boundary between the social and natural sciences is often blurred, as we explained earlier.

Our data suggests, as we elaborate in the following section, that when scientists, and to some extent policymakers, mention bioeconomy, they are mainly talking about using biological processes in new ways to drive sustainable energy production, or contribute to environmental protection. It is this that is seen to constitute a new economic regime. Again, this finding is supported by the work of Bugge et al. In their list of science journals with papers citing bioeconomy, the top four were: 'Biofuels, Bioproducts \& Biorefining-biofpr' (27 papers); 'Journal of the American Oil Chemists Society' (15 papers); 'Biomass and Bioenergy' (18 papers); and 'Journal of Cleaner Production' (12 papers). The journal 'Green Chemistry', despite only having 3 papers that used the concept, also generated the highest number of citations at 1056.

What we see in our data, and that of Bugge et al, is a complex picture in which a broad range of disciplines and fields are using the concept bioeconomy, but the peer-reviewed scientific literature tend to limit its definition to the use of industrial biotechnology to meet growing energy needs 
in a more sustainable way. This, as we discuss in more detail later, mirrors many of the early policy approaches to the bioeconomy (such as the OECDs), where new economies of the future based on sustainable bio-based products have become part of the collective policy imagination, which we can describe as sociotechnical imaginaries (Jasanoff and Kim, 2009). This is interesting given many social science articles, particularly those critical of the commodification processes and neoliberal assumptions that prefigure an expectant bioeconomy, tend to reference examples from red or green biotechnology to support their claims. Social scientists' understanding and interest in the bioeconomy does not therefore align with that of natural scientists. So there are multiple framings and meanings attached to the concept of bioeconomy, which have material consequences for the ways in which R\&D policy is structured, shaped, and understood. It is to these that we now turn.

\section{Multiple 'framings' and theories of bioeconomy and their material consequences}

Our analysis revealed that the concept of bioeconomy has been defined multiple ways in different contexts. Although in use before 2004, bioeconomy only gained traction and political salience from 2006, specifically as a term to describe emerging or nascent economic activities and opportunities from 'new biology'; that is the advances in molecular biology that accelerated in the 1990s and promised to revolutionize the industrial sectors of health, food, and environment (Wield, 2013; Wield et al., 2013). In an important 2006 report, The Bioeconomy to 2030: Designing a Policy Agenda, the OECD formally defined the bioeconomy as:

\footnotetext{
... the aggregate set of economic operations in a society that use the latent value incumbent in biological products and processes to capture new growth and welfare benefits for citizens and nations. These benefits are manifest in product markets through productivity gains (agriculture, health), enhancement effects (health, nutrition) and substitution effects (environmental and industrial uses as well as energy); additional
}

benefits derive more eco-efficient and sustainable uses of natural resources to provide goods and services to an ever growing population. (OECD, 2006: 1)

In an updated 2009 report, the OECD stated:

...the bioeconomy can be thought of as a world
where biotechnology contributes to a significant
share of economic output. The emerging
bioeconomy is likely to be global and guided
by principles of sustainable development and
environmental sustainability ... A bioeconomy
involves three elements: biotechnological
knowledge, renewable biomass, and integration
across applications. (OECD, 2009: 22)

These quotations provide a broad definition of bioeconomy, where new technological practices and economic regimes will extract latent value from natural biological processes to both meet sustainability goals and promote national competitiveness. The idea of latent value, which assumes biological objects and processes have both inherent and ascribed value, is shared by a set of scholars who talk about 'bio-value' and new processes of 'commodification' (Cooper, 2008; Novas and Rose, 2000; Parry, 2007; Sunder Rajan, 2006). These authors focus on new and emergent forms of 'biovalue', and are interested in how objects and practices that we might intuitively consider to be outside the conventional capitalist economy (e.g natural resources) become monetized and seen as a source of different forms of economic value. In his review of the concept 'neoliberalism', Harvey (2006) also talks about how a fundamental feature of neoliberalism is that it opens up new fields for capitalist accumulation in areas previously seen in terms of a public goods framework, such as population genetic resources. Brown's (2013) work on the contradictions in use and exchange value in the cord-blood economy also highlights some of the challenges of these different conceptions of value.

The uneasy alignment of capitalism and biotechnology research, and the different business models and value systems that are coming to define contemporary life science-based industrialisation (Wield et al., 2015), has been critiqued by many Science and Technology Studies (STS) 
scholars and bioethicists. The commodification aspects of the bioeconomy, and the co-production of so-called 'biovalue' (Cooper, 2008; Rose, 2001; Sunder Rajan, 2006; Waldby, 2002) is one approach. Others have contemplated the broader technical processes of accounting and assetisation that underlie the virtual bioeconomy and its valuation practices (Birch, 2007; Birch, 2017; Birch and Tyfield, 2013). These authors have unpacked the underlying assumptions of both practitioners within the bioeconomy, however defined, and critics who have sought to exceptionalise novel forms of biological material and ascribe it inherent value. Yet others have questioned the basis of what they suggest are promissory commercial narratives about a 'biotechnology revolution' (Hopkins et al., 2007), which become aligned with an imagined techno-future where current global challenges are ameliorated. Of course, some authors note that firms often consider more pessimistic scenarios, alongside their promissory claims, when, for instance, conducting foresight studies (Tutton, 2011).

The theory of bio-value itself has also been critiqued by some scholars (Birch and Tyfield, 2013; Birch, 2017) for not addressing the 'assetbased' aspects of the bioeconomy, and instead valorizing what are considered to be highly novel commodity aspects, which we discuss in more detail in the final section. Talk of 'latent value', which sees untapped potential in both conventional and new biological material, also tends to prioritize the sustainable, natural resource management aspects of the bioeconomy (white biotechnology), which we showed is predominant in the science and policy literatures.

The second quotation from the OECD more explicitly frames the bioeconomy as a vision of how advances in biotechnology can contribute to economic output and growth. Here, there is a clear alignment of investments in biotechnology research, capital, and perceived national competitiveness. This framing is also evident in the European Commission's approach to the bioeconomy, which has sought to make substantial investments in research addressing topics relevant to the sustainable production of new products based on biomass. This was a key component of the European Commission's 2012
Bioeconomy Strategy (European Commission, 2012), which we discuss later.

The accounts of policy-oriented organisations, captured in our literature search, tend to focus on the sustainable food and energy sectors and emphasise the need to respond to climate change and food security. As Hausknost et al confirm in a recent paper (Hausknost et al., 2017), 'green growth' through the industrial application of biotechnology has emerged as an important bioeconomy vision, or perhaps a socio-technical imaginary. So a predominant narrative is about creating new markets for industrial biotechnology, which recognizes opportunities to capture latent value in natural biological processes and accelerate the transition from a fossil-fuel economy. There is additional interest in the potential economic benefits of sustainable manufacturing and processing industries. Some regard this definition, which is rooted in the concept of 'biovalue' discussed above, as most meaningful and practical from a policy perspective (Brunori, 2013). Proponents claim multiple benefits, including the creation of high value jobs, lower emissions, energy security, reduction of dependence on subsidies, a growing agricultural sector, and even in some cases the stabilization of rural communities. This promissory and expectant discourse is part of the future-oriented vision of the European Commission as well as organisations like the OECD. We focus on these powerful policy actors precisely because they have played a significant role in the performative aspects of bioeconomy; shaping the nature of R\&D practices and the metrics used to ascribe different forms of economic and non-economic value.

There is a strong neoliberal flavor to some of these framings of bioeconomy (linking global problems, science, and economic growth, and monetizing what might be considered public resources, for instance). This was perspicuous in President Obama's 2012 National Bioeconomy Blueprint, when it stated: 'Technological innovation is a significant driver of economic growth, and the U.S. bioeconomy represents a growing sector of this technology-fueled economy' (The White House, 2012: 1). We do not take a strong normative stance on what many social scientists pejoratively claim are the neoliberal underpinnings of the 
bioeconomy. We are not, for example, seeking to criticize policy organisations that link bioeconomy, sustainability and economic growth. Nevertheless, we do find it interesting that the notion of the bioeconomy as a driver of sustainable growth, and as having unlimited potential to deliver economic and societal benefits, has been the subject of such criticism and debate. While many social scientists suggest that a neoliberal philosophy is driving policy, perhaps more importantly they argue this is ultimately based upon often unjustified speculative value propositions and ideologies. So there is a credibility gap between an imagined future and current reality. Cooper (2008), for instance, argues that the emergent biotechnology industries cannot be differentiated from neoliberalism's rise as a dominant political philosophy:

The biotech revolution ... is the result of a whole series of legislative and regulatory measures designed to relocate economic production at the genetic, microbial, and cellular level, so that life becomes, literally, annexed within capitalist processes of accumulation.(Cooper, 2008: 19)

Styhre and Sundgren (2011) describe the bioeconomy as the 'economic regime of accumulation where technoscientific know-how developed in the life sciences is capable of making the lived body a principal surface of economic value creation' (Styhre and Sundgren, 2011: 3) For these authors, bioeconomy and neoliberalism are intimately aligned, with the utility and vitality of life itself subject to the vagaries of speculative commodification (Sunder Rajan, 2006). Birch (2007) goes further in describing the bioeconomy as a 'virtual abstraction' of economic practices in which benefit and potential '....are intertwined concepts ... repeated numerous times throughout this policy literature, which essentialises and naturalises the claims made about its innovative potential'(Birch, 2007: 89). In an earlier article, Birch (2006) suggested that economic representations and practices are legitimation devices for policy, which generate self-fulfilling prophesies. This is particularly evident in the context of claims about the bioeconomy's importance for national competitiveness.

In all these policy examples, and their critiques, the bioeconomy is framed mainly as a political and economic project to support new forms of capitalism, rather than a scientific or technological endeavor. But what does it mean to say the bioeconomy is a political project? What does this framing tell us about the nature of the scientific practices that are both driving and being driven by the machinations of policy, government, and industry? These arguments need further unpacking.

\section{The bioeconomy as a political project}

Peterson and Krisjansen draw on the sociology of science and economic sociology to examine the sociopolitical significance of what they argue are promissory discourses enveloping discussions of the bioeconomy (Petersen and Krisjansen, 2015). They suggest these discourses have an important performative role in modern biopolitcs. Activities that in the past might have been treated separately in policy, such as the different biotechnology sectors and industries around health, agriculture, and energy/environment, are now viewed under the general rubric of bioeconomy. The authors question the validity of some of the assumptions underlying these promissory discourses, as well as the logic of lumping disparate scientific, technological, and industrial activities and sectors within an all-embracing category.

However, it is the political nature of the bioeconomy that is implicit in their analysis, which is shared by Goven and Pavone who, in their Polanyian analysis, describe it as a promissory construct to "...induce and facilitate some actions while deterring others; most explicitly it is meant to bring about a particular set of political-institutional changes that will shape the parameters of possible future action" (Goven and Pavone, 2015: 1). Although not doubting the science and policy communities' noble intent to use biotechnology to solve global challenges; the authors describe the world in which the bioeconomy operates as imagined; one where "... human and environmental disasters are averted because a particular political-institutional configuration facilitated the development of profitable technological solutions" (Goven and Pavone, 2015: 4). In a more recent paper, the authors argue: "Bioeconomy strategies position the bioeconomy as key to 'global competitiveness', while the need for 'global 
competitiveness' is taken for granted" (Pavone and Goven 2017: 7). They suggest this framing displaces alternative approaches that seek to address structural and endemic aspects of the global challenges facing society, and ultimately sustains the status quo. This view is consistent with Harvey's (2006) account of neoliberalism's damaging 'creative destruction', which emerges from the process of commodification and privatization, and an obsession with econometrics.

Similarly, Doezema and Hurlbut (2017) suggest dominant visions of the bioeconomy - i.e. as a political, neoliberal project in which the market is valorized above all else - reflect an 'imaginary of governance.' That is, they "...construct technoscience as the agent capable of enhancing social well-being, and outline the corollary political commitments that are prerequisite for desirable technological futures" (Doezema and Hurlbut, 2017: 50). Again, the argument here is that a promissory vision of a successful bioeconomy is suffused with assumptions and expectations about biotechnology's transformative potential. These authors see the OECD's Bioeconomy to 2030 Report and the US Bioeconomy Blueprint, for example, as exemplifying the aspirational political vision of technoscience as the ultimate solution to society's problems. In so doing, such reports 'draw upon and crystalize widely shared notions of the rights, roles, and responsibilities of political subjects in relation to both science and the state' (Doezema and Hurlbut, 2017: 50).

Hilgartner uses the term 'anticipatory enterprises' to describe organisations like the OECD and the European Commission. Such organisations are engaged in technological foresight, in which future-oriented expectations and imaginaries of technoscience are central. However, Hilgartner suggests that they are not simply seeking to anticipate the future. They are also seeking to shape or transform it. (Hilgartner 2007: 382.)

These powerful policy drivers to build a sustainable bioeconomy, whether or not their promissory visions are realistic, have an impact on research strategy and organizational practices, which is why we describe them as having a performative function. It is also why we consider them important objects of study. The hopes and expectations that are embedded within the reports of national and international policy institutions, governments, and commercial organisations, are not simply rhetoric. They have a material impact on what areas of science get funded and what kind of research is valued.

The bioeconomy, we suggest, is both a political and a scientific/technological project, in that old and new science and technology is being exploited to transform society and economy. When a particular conceptualization of bioeconomy becomes attached to innovation policy and strategy, this shapes behaviour in the communities that are responsible for developing and applying biotechnology research. Although the scientific community may see its activities and practices through the prism of basic science and technology, innovation policy is shaped by social and political exigencies.

As our analysis revealed, most of the scientific papers used bioeconomy to frame a set of scientific and technological challenges. Moreover, this literature reflected a vision of the bioeconomy as a facilitator of white biotechnology; using microorganisms or enzymes to create new biologicalbased products to meet sustainability objectives or to improve global agricultural production systems for food security. This mirrors the policy approaches to bioeconomy over the past decade. As McCormick and Kautto (2013: 2594) argue, "The principal products of the bio-economy are bio-based products and bioenergy", so this is where the primary focus has been, as evidenced by Golembiewski et al (2015) in their bibliometric analysis of the bioeconomy landscape (Golembiewski et al., 2015: 309). A large portion of our selected articles from the science and policy fields emphasized this specific challenge. So what is the impact of these framings in terms of the policy agendas that are actually shaping the contribution of life science-based research to the economy? There are important questions about the size of the bioeconomy and where is it heading. To address these, we now discuss attempts to measure the activities and practices constituted within the bioeconomy, and critically analyse this in the context of the theories and concepts of biovalue and promissory discourses outlined. 


\section{Value(s), valuation metrics and practices in the bioeconomy}

The way the bioeconomy concept is driving policy agendas and shaping industrial strategy raises questions about promissory value and valuation practices. This becomes salient when we look at attempts by policymakers and innovators to measure the size and growth potential of national and regional bioeconomies. As Hilgartner (2007) argues, realising the OECD's policy vision of an international bioeconomy requires a means to align the formal definition of bioeconomy (aggregate set of economic operations built on biological products etc.) with the everyday activities and practices that this abstract definition is used to represent. This:

... is not simply a matter of one-way reification, in the sense of treating an abstraction as if it had concrete existence; it is a process of iterative alignment that also involves making the abstraction more concrete by constructing techniques and institutional machinery capable of persuasively representing the activities (Hilgartner, 2007: 385).

Importantly, estimates of the economic contribution of activities and practices constitutive of the bioeconomy depend on the use of these calculative devices and techniques, which have political and commercial implications. Here, we look at three case examples; one from the UK, one from the US, and another at a pan-European level.

\section{Measuring the UK's bioeconomy}

A recent report by Capital Economics, TBR, and E4tech, on behalf of the UK's Biotechnology and Biological Sciences Research Council (BBSRC) and the Department for Business, Innovation and Skills (Bauen et al., 2016), presents a sophisticated evidence-based review of the contribution of the bioeconomy to UK growth and competitiveness. Like the OECD, this report defines the bioeconomy as encompassing "all economic activity derived from bio-based products and processes", and suggests that: "These contribute to sustainable and resource-efficient solutions to the challenges we face in food, chemicals, materials, energy production, health and environmental protection"
(Bauen et al., 2016: 3). Interestingly, the report clarifies that the bioeconomy builds on activities that involve 'transformative processes' -as well as their related upstream and downstream activities - around biological resources. This includes both conventional activities like growing crops and rearing livestock, as well as advanced bio-based products.

So the report is interested in both new, advanced biological innovations, as well as any activity or process that involves manipulation or conversion of biological resources into products that contribute to the economy. This broad definition increases the scale and potential value of the UK bioeconomy. The report states:

\begin{abstract}
The transformational bioeconomy comprising agriculture and fishing, forestry and logging, water and remediation activities, food products and beverages and industrial biotechnology and bioenergy accounts for 3.5 per cent of gross value added in the United Kingdom ( $£ 56.0$ billion in 2014), which is a little more than the wholesale trade and more than double the figure for the crude petroleum and natural gas extraction and mining industries (Bauen et al., 2016: 5)
\end{abstract}

When adding upstream and downstream activities related to this bioeconomy, the report states that $£ 220$ billion is generated in gross value added, supporting 5.2 million jobs. Furthermore, it suggests the UK bioeconomy plays a major role in attracting inward investment. The report states that in recent years the bioeconomy has performed much better than the economy as a whole, having previously lagged behind. In terms of European competitiveness, the report argues that the UK bioeconomy is smaller than in some other major European countries, in terms of gross value added, but that if contributions from agricultural activities were removed from the analysis, the UK bioeconomy is larger than Italy and Spain, and comparable to France. So here we see how measurements of growth potential (the report estimates that output could grow by $13 \%$ in the coming years) and international comparisons, which are important in policy contexts to align innovation, investment, and wealth creation; can significantly shift depending on the inclusion and exclusion criteria. 
Overall, this is a sophisticated report in that it provides sector-by-sector data on jobs and economic activity, and does not limit the analysis to white biotechnology, so it is adopting a broad definition of bioeconomy. However, it does not enable us to estimate the specific contribution of the newer and advanced biotechnological innovations, which begs the question of whether by being so inclusive, such measurements and estimations render the bioeconomy concept meaningless. Nevertheless, as a political project, the bioeconomy concept is clearly successful in appropriating economic activities and generating the promise of future value - albeit comparative and the creation of jobs.

\section{Contribution of the US bioeconomy}

In the US, a report by the Bioindustry Association (BIO), a trade body, and Battelle, a not-for profit $R \& D$ organisation, assessed the contributions made by five broad bioscience-based sectors to the US economy (Battelle et al., 2014). This report attempts to measure the contribution of certain bio-based sectors to the US economy, using data on sectoral employment and wages, R\&D expenditures, patents, and various kinds of conventional performance metrics. Like the BBSRC report, the most revealing aspect is what is included and excluded in the analysis. The five sectors analysed were: 'Agricultural Feedstock and Chemicals'; 'Drugs and Pharmaceuticals'; 'Medical Devices and Equipment'; 'Research, Testing and Medical Laboratories'; and 'Biosciences-Related Distribution'. Overall, the report presents a sanguine picture of the success of the bio-industries, stating "... bioscience in the $21^{\text {st }}$ Century has been a consistent producer of innovation-driven economic growth - generating jobs, income and output growth for those regional economies with key bioscience assets" (Battelle et al. 2014: 2).

The data presented show, like the BBSRC report, that the bioscience industries have responded better to the financial crisis of 2007/2008 than private industry as a whole. The sector has continued to grow in terms of job creation. Furthermore, in terms of gross economic output, the report reveals that in all five sectors nominal output continued to expand significantly from 2001-2012. The report also shows that, apart from R\&D funding, which had been relatively flat until 2014, most other metrics of value (employment, patents, venture funding etc.) had risen. However, it is important to note that job growth had declined in the drug development and agrobiotechnology sectors. Nevertheless, we again return to the critical issue of what is included and excluded in the selection of activities, practices, and material objects that are presented as constitutive of the bioeconomy. For example, in the 'Drugs and Pharmaceuticals category', no distinction is made between advanced bio-based R\&D and conventional small-molecule drug development, so the specific contribution of biology to the health-related bioeconomy cannot be extracted from the analysis. One might legitimately ask if this aspect of drug innovation is more or less valuable as a driver of employment, economic growth, and indeed patient health and wellbeing, than conventional drugs? However, this question cannot be answered by the data provided in the report.

An editorial in the journal Nature Biotechnology (Nature Biotechnology, 2014), provided a nice critique of this report on the grounds that the size of the bioeconomy is a constantly moving target precisely because analysts are too inclusive in some cases, and not inclusive enough in others. It is therefore impossible to make accurate and meaningful judgements of its scale and scope. For example, the report includes firms that manufacture fertilizer in its 'agricultural, feedstock and chemicals' sector, when it might have been more justifiable to categorise this as part of the chemicals rather than biotech industry. This is similar to our earlier argument about the lack of a clear distinction between chemical and bio-based drug development. In terms of the "medical devices sector", the editorial argues the report accepts the US Department of Labor's definition, which includes "... manufacturers of clamps, canulae and bone drills as well as syringes, knives and medical thermometers" (Nature Biotechnology 2014: 598). These are not activities and products one would naturally associate with innovative life sciences, yet they are being captured in analyses of the economic contribution of the bioeconomy.

The Nature editorial reserves the greatest criticism for the categories excluded from the 
analysis, and the employment data is particularly interesting. "...the report tallies up the number of bioscience patents .... but does not enumerate bioscience patent lawyers. It notes the gradual increase in venture capital spending, but does not count up venture investors" (Nature Biotechnology, 2014: 598). Furthermore, the report does not factor the increase in number of jobs within regulatory agencies and reimbursement agencies, as well as those in health insurance companies and reimbursement agencies, which are more relevant to the bioeconomy than jobs associated with conventional medical device development, or manufacture of chemicals for the agricultural sectors. Indeed, the size of the bioeconomy could turn out to be much larger than the report suggests, if all these additional jobs and activities were included, and others excluded.

Scepticism of many conventional attempts to capture the economic contribution of the bioeconomy is shared by Carlson (2016). Summarising the problem, he states:

\footnotetext{
Current understanding of the biotech sector is hampered by inconsistencies in usage and definition of 'biotechnology' and 'bioeconomy' ... These words may be used in reference only to pharmaceuticals (or biopharmaceuticals, or biologics, depending on one's definition), genetically modified (GM) crops, or public companies whose primary revenues rely on biological technologies, thereby muddling an integrated description of the industry ... Beyond linguistic imprecision, a lack of data resulting from inadequate characterization of the economy hampers any assessment of the economic size and scope of biotech. (Carlson, 2016: 247).
}

Carlson proceeds to point out that even in the US, which dominates global biotech, there is no official means to distinguish biological from non-biological technologies and products. For example, a chemical manufactured using biologics is treated similarly to one produced from fossil petroleum. The former may displace the latter "on the basis of price or preference, yet revenues now accrue to a category that includes petrochemicals." (Carlson, 2016: 247) So under the present system of classification, revenue accruing from a novel biomole- cule could, according to Carlson, be misattributed to fossil fuels.

\section{The value of the European bioeconomy}

As a key region promoting the bioeconomy, the European Union's 2012 'Bioeconomy Strategy' and its 2017 review (European Commission, 2017) touts the importance of a market estimated in 2009 to be worth over 2 trillion euros and responsible for 20 million jobs (M'Barek et al., 2014). The key objectives outlined in the 2012 strategy are; 1) ensuring food security; 2) managing natural resources sustainably; 3 ) reducing dependence on non-renewables; 4) climate change mitigation and adaptation; and 5) creating jobs and ensuring EU competitiveness (European Commission, 2012). In a recent review of this strategy (European Commission, 2017), the Commission suggested the policy context within which the bioeconomy operates has significantly changed since the 2012 strategy was developed (particularly around sustainability goals). This may require a refocus on key elements. However, it noted there had been success on some of the deliverables of the original strategy, particularly around the mobilization of funding for research and innovation, under Horizon 2020, and the development of standards for bio-based products, as well as key contributions to European employment and income generation.

A recent paper takes the Commission's strategy and definition of bioeconomy and attempts to define a methodology to quantify two bioeconomy indicators - turnover and employment - using Eurostat data (Ronzon et al., 2017). This work was conducted in collaboration with the European Commission's Joint Research Centre (JRC). The authors conclude that:

The bioeconomy employed approximately 18.6 million people in the EU-28 in 2014, generating turnover around EUR 2.2 trillion. Between 2008 and 2014, employment in the European bioeconomy contracted, with the loss of nearly 2 million people employed. Agriculture and the manufacture of food, beverages and tobacco constituted three quarters of the jobs and two thirds of the turnover of the European Bioeconomy (Ronzon et al., 2017: 7). 
More detail on the numbers and metrics can be found in a report by Piotrowski et al (2018). The authors discovered that the biomass sectors were the most labour-intensive, particularly agriculture and fishing. In terms of overall turnover, half of the 2 trillion EUROS is accounted for by the food and beverage sector, a quarter from agriculture and forestry, and the remainder form what are defined as 'biobased industries' (which included plastics and chemicals, pharmaceuticals, paper products, forest-based industries, textiles, biofuels and bioenergy). Again, we see how a very expansive and inclusive definition of bioeconomy can be used to make claims about current and future value. Disentangling from these figures the specific contributions of, say, advanced life sciences, and discounting what might be categorised as old or conventional biological activities or processes is not possible. The bioeconomy therefore becomes a catch-all term for an array of practices, activities and economic sectors that, together, are shown to generate value, support national competitiveness, and solve grand global challenges.

\section{Discussion and conclusions: new approaches to measurement and value}

What all these national and regional reports and strategies exemplify is how measurement, and the application of different tools and metrics, can be used to drive different narratives about the scale, scope, and value of the bioeconomy and its constitutive activities and practices. Most advanced nations attempt to measure their bioeconomies and evaluate their national competitiveness. So we have Dutch estimates of the size of its Biobusiness (Heijman, 2016), and German attempts to measure the bioeconomy within the general economy (Efken et al., 2016). The idea of a vibrant bioeconomy is of strategic importance for nations and regions as they justify public investments in life sciences and industrial biotechnology.

What is interesting in all these reports, which have a performative role in shaping industrial strategy, is that they operate with different metrics for evaluation, making cross-country comparisons difficult. Also, they adopt a very narrow definition of value; one linked inextricably to crude and conventional economic metrics, like profitability, employment, GDP etc. If we take some of these crude economic metrics at face value, they suggest that the supposed biotechnology revolution is not perhaps as revolutionary and profitable as has been assumed; instead being based on unfulfilled expectations driven by promissory discourses. As Birch argues, despite the global biotechnology industry increasing its market capitalization over time,

$$
\begin{aligned}
& \text {... in } 2014 \text { the life sciences sector was neither } \\
& \text { producing proportionally more products and } \\
& \text { services nor proportionally higher revenues than } \\
& \text { four or five years earlier ... [This illustrates] how } \\
& \text { uncertain and volatile value and valuations are in } \\
& \text { the bio-economy, and how disassociated they can } \\
& \text { often seem to be from the development of new } \\
& \text { products and services (Birch, 2017:2) }
\end{aligned}
$$

Birch is interested in this contradiction between the high financial valuations placed on the biotechnology sector - partly sustained by reports suggesting the size and contribution of the bioeconomy is growing - and the failure of this to engender the products that public investments in biotechnology continually promise are imminent. One answer is that current value is simply based on the promissory visions and expectations of future economic returns from products, and this is what interests many scholars focused on biovalue and the commodification processes underlying the neoliberal bioeconomy. However, Birch's argument is that we need to look beyond this to the 'assetisation' processes; that is the financial technologies, knowledges, and practices that enable things to be transformed into assets and generate value. This leads him to consider value and valuation beyond the intrinsic or latent properties of the tangible biological objects themselves, or their related intangible products such as IP, which would be consistent with a commoditybased analysis. Instead, he looks at the financial valuation of the firms themselves, and their assets, arguing this is ultimately where the value is realised (Birch, 2017: 3). The outcome of this analysis is that "... value is constituted primarily by the social practices of the political-economic actors who configure the financial value and valuation of firms" (Birch, 2017: 3). 
While this approach is still focused primarily on value in a commercial/economic sense, opening up value to include the social practices of valuation enables us to think about the bioeconomy in a more interesting and sophisticated way. This approach begs the question of whether the value allocated to the bioeconomy by different actors, and the transformative activities and ways of organising research that have been precipitated by governments, policymakers, and industry, should be evaluated primarily through crude economic metrics, whether that be commodity or asset value. The field of valuation studies (Helgesson and Muniesa, 2013) shows we can capture both the objective and subjective elements of value and make better sense of the economic and noneconomic evaluation practices that frame different accounts of benefit and worth (Lamont, 2012). A broader, inclusive approach to value forces us to consider the multiple ways in which economic and non-economic value is enacted and performed in different professional and social contexts (Mittra, 2016; Stark, 2009).

In the context of the bioeconomy, this approach to value enables us to illuminate the transformational changes that political projects, driven by advances in science and technology, have had on numerous industrial sectors and the ways in which their R\&D is organised. It moves beyond narrow questions about whether the life sciences are meeting their early promise and satisfying expectations of delivering new products and economic returns, to looking at how interdisciplinary and collaborative practices are emerging alongside new business models and value systems in an attempt to make advanced biology work to solve global problems.

Policymakers, industrialists, scientists, publics, and a whole range of other stakeholders are concerned about the value and worth of innovation in the health, agriculture, and environmental sectors, as our literature analysis and critical review of official reports has shown. Nevertheless, measurement does guide behaviour, and attempts to talk about the bioeconomy as if its objects and practices were simple to define and measure can obscure as much as they reveal. As we have shown, the concept can appear meaningless given the diverse inclusion and exclusion criteria, which can affect estimations of value and worth. Of course, it is important to note that this strategy has been very successful as a political project, and ensured resources have been allocated to sectors and organisations that have sought to enact these promises, hopes, and expectations. The trends in the science and social science literatures that we identified, particularly the ways in which different disciplines have focused on very different sectors and application areas, further highlights the complexity and diversity of framing. The scientific papers tend to mirror policy accounts that see the bioeconomy rooted in issues of sustainability, with the social sciences more critical of bioeconomy and likely to reference green and red biotechnology as their key examples of commodification and assetisation processes.

To conclude, we have attempted in this paper to trace the emergence and evolution of the concept of bioeconomy and show how it has been framed and used strategically by various constituencies as a political, scientific/technological, and economic project to meet regional and global challenges. Our starting point was to ask: what is the bioeconomy, how has it been used in different fields, and how might it be best understood and valued? It turned out that the answer to the last part, which is a normative question, is dependent on the answers to the first part. How the bioeconomy is defined, both formally and informally, and what activities and practices are considered to be its immanent features, determines its scale, scope, and ultimately the value that different stakeholders place on it. Nevertheless, by critiquing the concept of bioeconomy and the valuation tools and calculative devices used to measure it, we have shown that a broader conceptualisation of value that takes seriously underlying social practices, would perhaps better inform our understanding of the contributions made by the different sectors within the bioeconomy.

While it might be meaningless as a broad and highly inclusive concept, the bioeconomy, as a distinct economic regime that captures the new activities and practices of advanced biotechnology, can be studied in a meaningful and useful way. However, to do so, we need far more precision in the measurement tools we use; be highly cautious of reports that use inappropriate 
inclusion or exclusion criteria that often artificially inflate the economic contributions of the bioeconomy; and we perhaps need to stop prioritising white biotechnology as the key driver. We have shown that doing so obfuscates or downplays the important contributions of red and green biotechnology, and also elides the fact that benefits and limitations, including accounts of value, may vary between the different categories. 


\section{References}

Battelle et al. (2014) Battelle / BIO State Bioscience Jobs, Investments and Innovation 2014. Available at: https:// www.bio.org/sites/default/files/files/Battelle-BIO-2014-Industry.pdf (accessed 15.7.2018).

Bauen A, Chambers G, Houghton M, Mirolavi B, Nair S and Natress L (2016) Evidencing the Bioeconomy, A report by Capital Economics, TBR and E4Tech for the BBSRC and BIS, Available at: https:// bbsrc.ukri.org/documents/1607-evidencing-the-bioeconomy-report/ (accessed 15.7.2018). DOI: 10.1787/9789264193321-en.

Birch K (2006) The Neoliberal Underpinnings of the Bioeconomy: the Ideological Discourses and Practices of Economic Competitiveness. Genomics, Society and Policy 2(3): 1-15.

Birch K (2007) the Virtual Bioeconomy : the ' Failure ' of Performativity and the Implications, Scandinavian Journal of Social Theory 14: 83-99.

Birch K (2017) Rethinking Value in the Bio-economy. Science, Technology, \& Human Values 42(3): 460-490. DOI: $10.1177 / 0162243916661633$.

Birch K and Tyfield D (2013) Theorizing the Bioeconomy. Science, Technology \& Human Values 38(3): $299-327$. DOI: $10.1177 / 0162243912442398$.

Borup M, Brown N, Konrad K and van Lente H (2006) The sociology of expectations in science and technology. Technology Analysis and Strategic Management, 18 (3-4): 285-298

Bowker GC and Star SL (2000) Sorting Things Out: Classification and Its Consequences. Cambridge: MIT Press.

Brown N (2013) Contradictions of value: Between use and exchange in cord blood bioeconomy. Sociology of Health and IIIness 35(1): 97-112. DOI: 10.1111/j.1467-9566.2012.01474.x.

Brunori G (2013) Biomass, Biovalue and Sustainability: Some Thoughts on the Definition of the Bioeconomy. EuroChoices 12(1): 48-52. DOI: 10.1111/1746-692X.12020.

Bugge MM, Hansen T and Klitkou A (2016) What is the bioeconomy? A review of the literature. Sustainability 8 (7): 1-22. DOI: 10.3390/su8070691.

Callon M, Méadel C and Rabeharisoa V (2002) The economy of qualities. Economy and Society 31(2): $194-217$. DOI: $10.1080 / 03085140220123126$.

Carlson R (2016) Estimating the biotech sector's contribution to the US economy. Nature Biotechnology 34(3): 247-255. DOI: 10.1038/nbt.3491.

Cooper M (2008) Life as Surplus. Biotechnology and Capitalism in the Neoliberal Era. Seattle: University of Washington Press.

Doezema T and Hurlbut JB (2017) Technologies of Governance: Science, State and Citizen in Visions of the Bioeconomy. In: Pavone V and Goven J (eds) Bioeconomies: Life, Technology, and Capital in the 21st Century. Basingstoke: Palgrave Macmillan, pp. 49-71.

Efken J, Dirksmeyer W, Kreins P and Knecht M (2016) Measuring the importance of the bioeconomy in Germany : Concept and illustration. NJAS - Wageningen Journal of Life Sciences 77: 9-17. DOI: 10.1016/j. njas.2016.03.008.

European Commission (2012) Innovating for Sustainable Grow th: A Bioeconomy for Europe. Brussels.

European Commission (2017) Review of the 2012 European Bioeconomy Strategy. Brussels. DOI: 10.2777/8814.

Golembiewski B, Sick N and Bröring S (2015) The emerging research landscape on bioeconomy: What has been done so far and what is essential from a technology and innovation management perspective? Innovative Food Science and Emerging Technologies 29: 308-317. DOI: 10.1016/j.ifset.2015.03.006.

Goven J and Pavone V (2015) The Bioeconomy as Political Project: A Polanyian Analysis. Science, Technology \& Human Values 40(3): 302-337. DOI: 10.1177/0162243914552133. 
Harvey D (2006) Neo-liberalism as creative destruction, Geografiska Annaler: Series B, Human Geography(2): $145-158$.

Hausknost D, Schriefl E, Lauk C and Kalt G (2017) A Transition to Which Bioeconomy? An Exploration of Diverging Techno-Political Choices. Sustainability 9(4): 1-22. DOI: 10.3390/su9040669.

Heijman W (2016) How big is the bio-business ? Notes on measuring the size of the Dutch bio-economy. NJAS - Wageningen Journal of Life Sciences 77: 5-8. DOI: 10.1016/j.njas.2016.03.004.

Helgesson C-F and Muniesa F (2013) For what it's worth: an introduction in valuation studies. Valuation Studies 1(1): 1-10. DOI: 10.3384/v.

Helgesson C-F and Kjellberg H (2013) Introduction: Values and Valuations in Market Practice. Journal of Cultural Economy 6(4): 361-369. DOI: 10.1080/17530350.2013.838187.

Hilgartner S (2007) Making the Bioeconomy Measurable: Politics of an Emerging Anticipatory Machinery. BioSocieties 2(3): 382-386. DOI: 10.1017/S1745855207005819.

Hopkins MM, Martin PA, Nightingale P, Kraft A and Mahdi S (2007) The myth of the biotech revolution: An assessment of technological, clinical and organisational change. Research Policy 36(4): 566-589. DOI: 10.1016/j.respol.2007.02.013.

House TW (2012) National Bioeconomy Blueprint, April 2012. Industrial Biotechnology 8(3): 97-102. DOI: 10.1089/ind.2012.1524.

Jasanoff S and Kim SH (2009) Containing the atom: Sociotechnical imaginaries and nuclear power in the United States and South Korea. Minerva 47(2): 119-146. DOI: 10.1007/s11024-009-9124-4.

Lamont M (2012) Toward a Comparative Sociology of Valuation and Evaluation. Annual Review of Sociology 38(1): 201-221. DOI: 10.1146/annurev-soc-070308-120022.

M'Barek R, Philippidis G, Suta C et al. (2014) Observing and analysing the Bioeconomy in the EU - Adapting data and tools to new questions and challenges. Bio-based and Applied Economics 3(1): 83-91. DOI: 10.13128/BAE-14189.

McCormick K and Kautto N (2013) The Bioeconomy in Europe: An Overview. Sustainability 5(6): 2589-2608. DOI: $10.3390 /$ su5062589.

Mittra J (2016) The New Health Bioeconomy. New York: Palgrave Macmillan. DOI: 10.1057/9781137430526.

Nature Biotechnology (2014) How big is the bioeconomy? Nature Biotechnology 32(7): 598-598. DOI: 10.1038/nbt.2966.

Novas C and Rose N (2000) Genetic risk and the birth of the somatic individual. Economy and Society 29(4): 485-513. DOI: 10.1080/03085140050174750.

OECD (2006) The Bioeconomy to 2030: Designing a Policy Agenda. Paris.

OECD (2009) The Bioeconomy to 2030. Agenda. Paris. DOI: 10.1787/9789264056886-en.

Parry B (2007) Cornering the Futures Market in 'Bio-epistemology'. BioSocieties 2(3): 386-389. DOI: 10.1017/ S1745855207005820.

Pavone V and Goven J (2017) Introduction. In: Pavone V and Goven J (eds) Bioeconomies: Life, Technology, and Capital in the 21st Century. Basingstoke: Palgrave Macmillan, pp. 1-22.

Petersen A and Krisjansen I (2015) Assembling 'the bioeconomy': Exploiting the power of the promissory life sciences. Journal of Sociology 51(1): 28-46. DOI: 10.1177/1440783314562314.

Piotrowski S, Carus M and Carrez D (2018) The European Bioeconomy in Figures, Biobased Industries Consortium. Brussels.Available at: https://biconsortium.eu/sites/biconsortium.eu/files/documents/European_ Bioeconomy_in_Figures_2008-2015_06042018.pdf (accessed 15.08.18). 
Ronzon T, Piotrowski S, M'Barek R and Carus M (2017) A systematic approach to understanding and quantifying the EU 's bioeconomy. Bio-Based and Applied Economics 6(1): 1-17. DOI: 10.13128/BAE-20567.

Rose N (2001) The Politics of Life Itself. Theory, Culture \& Society 18(6): 1-30. DOI: 10.1177/02632760122052020.

Stark D (2009) The Sense of Dissonance. Accounts of Worth in Economic Life. New Jersey: Princeton University Press. DOI: 10.1007/s00191-011-0251-3.

Styhre A and Sundgren M (2011) Venturing into the Bioeconomy: Professions, Innovation, Identity. Basingstoke: Palgrave Macmillan.

Sunder Rajan K (2006) Biocapital. The Constitution of Postgenomic Life. Durham: Duke University Press

Tutton R (2011) Promising pessimism: Reading the futures to be avoided in biotech. Social Studies of Science 41(3): 411-429. DOI: 10.1177/0306312710397398.

Waldby C (2002) Stem Cells, Tissue Cultures and the Production of Biovalue. Health: An Interdisciplinary Journal for the Social Study of Health, Illness and Medicine 6(3): 305-323. DOI: 10.1177/136345930200600304.

Wield D (2013) Bioeconomy and the global economy: Industrial policies and bio-innovation. Technology Analysis and Strategic Management 25(10): 1209-1221. DOI: 10.1080/09537325.2013.843664.

Wield D, Hanlin R, Mittra J and Smith J (2013) Twenty-first century bioeconomy: Global challenges of biological knowledge for health and agriculture. Science and Public Policy 40(1): 17-24. DOI: 10.1093/scipol/ scs116.

Wield D, Tait J, Chataway J, Mittra J and Mastroeni M (2015) Conceptualising and practising multiple knowledge interactions in the life sciences. Technological Forecasting and Social Change 116: 308-315. DOI: 10.1016/j.techfore.2016.09.025. 